\title{
Lapatinib plus Capecitabine for Brain Metastases in Patients with Human Epidermal Growth Factor Receptor 2-Positive Advanced Breast Cancer: A Review of the Anatolian Society of Medical Oncology (ASMO) Experience
}

\author{
Bulent Cetin $^{\mathrm{a}} \quad$ Mustafa Benekli $^{\mathrm{a}}$ Berna Oksuzoglu ${ }^{\mathrm{b}}$ \\ Ibrahim Turker $^{b}$ Mehmet A. Kaplan $^{e}$ Dogan Koca $^{f}$ \\ Alper Sevinc ${ }^{\text {h }}$ Veli Berk ${ }^{i}$ Abdurrahman Isıkdogan ${ }^{\mathrm{e}}$ \\ Lokman Koral $^{c} \quad$ Arife Ulas $^{b}$ Faysal Dane $^{d}$ \\ Cem Boruban ${ }^{c}$ Burcak Yilmaz ${ }^{9}$ \\ Ugur Coskun ${ }^{a}$ Suleyman Buyukberber ${ }^{\mathrm{a}}$ \\ Dogan Uncuj Hakan Harputluogluk
}

${ }^{a}$ Department of Medical Oncology, Gazi University Faculty of Medicine, bepartment of Medical Oncology, Dr. Abdurrahman Yurtaslan Training and Research Hospital, Ankara, 'Department of Medical Oncology, Selcuk University Meram Faculty of Medicine, Konya, 'Department of Medical Oncology, Marmara University Faculty of Medicine, Istanbul, ${ }^{e}$ Department of Medical Oncology, Dicle University Faculty of Medicine, Diyarbakir,

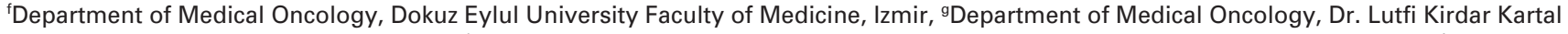
Training and Research Hospital, Istanbul, 'Department of Medical Oncology, Gaziantep University Faculty of Medicine, Gaziantep, 'Department of Medical Oncology, Erciyes University Faculty of Medicine, Kayseri, 'Department of Medical Oncology, Numune Training and Research Hospital,

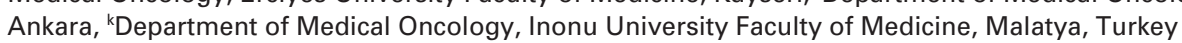

\section{Keywords}

HER2 - Metastatic breast cancer · Lapatinib · Brain metastases

\section{Summary}

Background: We investigated the clinical outcome of patients with brain metastases (BMs) from human epidermal growth factor receptor 2-positive (HER2+) metastatic breast cancer (MBC) treated with lapatinib and capecitabine (LC). Patients and Methods: A total of 203 patients with HER2+ MBC, who had progressed after trastuzumab-containing chemotherapy, were retrospectively evaluated in 11 centers between September 2009 and May 2011. 85 patients who had developed BMs before the initiation of treatment with LC were included. All patients had received prior cranial radiotherapy. All patients were treated with the combination of lapatinib $(1,250 \mathrm{mg} / \mathrm{day}$ continuously) and capecitabine $\left(2,000 \mathrm{mg} / \mathrm{m}^{2}\right.$ on days $1-14$ of a 21-day cycle). Results: The median follow-up was 10.5 months (range 1-38 months). An overall response rate of $27.1 \%$ was achieved, including complete response in $2(2.4 \%)$ and partial response in $21(24.7 \%)$ patients. Median progression-free survival was 7 months (95\% confidence interval (Cl) 5-9), with a median overall survival of 13 months (95\% Cl 9-17). The most common side effects were hand-foot syndrome $(58.8 \%)$, nausea $(55.3 \%)$, fatigue $(48.9 \%)$, anorexia $(45.9 \%)$, rash $(36.5 \%)$, and diarrhea (35.4\%). Grade 3-4 toxicities were hand-foot syndrome $(9.4 \%)$, diarrhea $(8.3 \%)$, fatigue $(5.9 \%)$, and rash $(4.7 \%)$. There were no symptomatic cardiac events. Conclusion: LC combination therapy was effective and well-tolerated in patients with HER2+ MBC with BMs, who had progressive disease after trastuzumab-containing therapy.
Schlüsselwörter

HER2 - Metastasiertes Mammakarzinom · Lapatinib . Hirnmetastasen

\section{Zusammenfassung}

Hintergrund: Wir haben das klinische Outcome von Patientinnen mit Hirnmetastasen eines HER2 (human epidermal growth factor receptor 2)-positiven metastasierten Mammakarzinoms unter Behandlung mit Lapatinib und Capecitabin (LC) evaluiert. Patientinnen und Methoden: Insgesamt wurden 203 Patientinnen mit HER2-positivem metastasierten Mammakarzinom, bei denen es zu einem Krankheitsfortschreiten unter Trastuzumab enthaltender Therapie gekommen war, zwischen September 2009 und Mai 2011 in 11 Behandlungszentren retrospektiv evaluiert. 85 Patientinnen, die vor dem Beginn der LC-Behandlung Hirnmetastasen entwickelt hatten, wurden in die Studie aufgenommen. Alle Patientinnen waren zuvor einer kranialen Radiotherapie unterzogen worden, und alle erhielten gleichermaßen eine Kombination aus Lapatinib (1250 mg/d kontinuierlich) und Capecitabine (2000 mg/m² an Tag 1-14 eines 21-tägigen Zyklus). Ergebnisse: Das mittlere Follow-Up betrug 10,5 Monate (Spanne 1-38 Monate). Eine Gesamtansprechrate von $27,1 \%$ wurde erreicht, inklusive eines kompletten Ansprechens bei 2 (2,4\%) und eines Teilansprechens bei $21(24,7 \%)$ Patientinnen. Das mittlere progressionsfreie Überleben war 7 Monate $(95 \%$ Konfidenzinterval (KI) 5-9) mit einem mittleren Gesamtüberleben von 13 Monaten (95\%-KI 9-17). Die häufigsten Nebenwirkungen waren Hand-Fuß-Syndrom (58,8\%), Übelkeit (55,3\%), Fatigue $(48,9 \%)$, Anorexie $(45,9 \%)$, Hautausschlag $(36,5 \%)$ und Durchfall (35,4\%). Als Toxizitäten vom Grad 3-4 traten HandFuß-Syndrom $(9.4 \%)$, Durchfall $(8,3 \%)$, Fatigue $(5,9 \%)$ und Hautausschlag $(4,7 \%)$ auf. Symptomatische kardiovaskuläre Nebenwirkungen wurden nicht beobachtet. Schlussfolgerung: Die LCKombinationstherapie war bei Patientinnen mit HER2-positivem metastasierten Mammakarzinom mit Hirnmetastasen, bei denen es nach trastuzumabhaltiger Therapie zu einem Progress gekommen war, effektiv und wurde gut toleriert. 


\section{Introduction}

Approximately $20-25 \%$ of all breast cancers are human epidermal growth factor receptor 2-positive (HER2+) and have historically been associated with poorer disease-free survival (DFS) and overall survival (OS) [1]. For patients with HER2+ metastatic breast cancer (MBC), the use of humanized monoclonal antibody trastuzumab (Herceptin ${ }^{\circledR}$, Genentech, San Francisco, CA, USA) in combination with chemotherapy has become the standard of care. Approximately one third of patients with $\mathrm{MBC}$ treated with trastuzumab-containing therapy develop brain metastases (BMs) [2, 3]. Concerns have also been raised about high rates of BMs following systemic response to trastuzumab. Trastuzumab does not fully cross the blood-brain barrier, making the brain a 'sanctuary' site $[4,5]$. Recently, a literature-based meta-analysis of randomized phase III clinical trials including trastuzumab as adjuvant therapy for early-stage breast cancer demonstrated that patients receiving trastuzumab therapy had a significantly higher risk for developing central nervous system (CNS) metastases compared to the patients treated with non-trastuzumab-containing regimens (relative risk 1.57, 95\% confidence interval (Cl) 1.03-2.37) [6]. Increased incidence of BMs in MBC limits the benefits of new systemic treatment modalities. Current treatments for BMs are palliative, including stereotactic radiosurgery or whole-brain radiotherapy (WBRT). Treatment options for CNS metastases from HER2+ MBC remain limited, while only a few prospective trials have been conducted [7, 8]. Lapatinib (Tykerb $^{\circledR}$, GlaxoSmithKline, Philadelphia, PA, USA) was approved in combination with capecitabine in patients with HER2+ MBC after progression under trastuzumab treatment based on a pivotal phase III study [9]. Compared to trastuzumab, lapatinib shows restricted but improved brain uptake by reaching levels up to one-quarter of those in plasma [10]. Lapatinib may reduce the risk of disease progression in the CNS based on the results from exploratory analyses performed from the pivotal phase III trial [11]. In this regard, the present study was undertaken to evaluate the clinical efficacy and adverse effect profile of lapatinib + capecitabine (LC) combination therapy in patients with HER2+ MBC and BMs, who progressed after trastuzumab therapy.

\section{Patients and Methods}

\section{Patients}

A total of 203 patients with HER2+ MBC, who received LC after progression following trastuzumab-containing chemotherapy, were retrospectively identified from 11 centers between September 2009 and May 2011. Of those, 85 patients who had developed BMs before the initiation of LC treatment were eligible to be included in this retrospective multicenter study. BMs were confirmed by magnetic resonance imaging or computed tomography scan. Eligible patients were females, $\geq 18$ years of age, with HER2+ MBC and 3+ staining by immunohistochemistry or evi- dence of gene amplification by fluorescence in situ hybridization. Patients had metastatic disease that progressed on their most recent treatment regimen which must have included trastuzumab. Patients were required to have a left ventricular ejection fraction (LVEF) within institutional normal limits, an absolute neutrophil count of at least $1,000 / \mu 1$, a platelet count of at least $75,000 / \mu \mathrm{l}$, bilirubin no more than 1.5 times the upper limit of normal (ULN), aspartate aminotransferase (AST) and alanine aminotransferase (ALT) no more than 5 times the ULN, and a creatinine clearance of at least $25 \mathrm{ml} / \mathrm{min}$

\section{Treatment}

Patients were treated with lapatinib $1,250 \mathrm{mg}$ orally once daily plus capecitabine $1,000 \mathrm{mg} / \mathrm{m}^{2}$ orally twice daily on days 1-14 every 21 days until disease progression. Dose reductions and delays for lapatinib- and/ or capecitabine-related toxic effects were done by the treating physician. Data on demographics, clinical outcome, and toxicity were collected based on retrospective evaluation of medical records for the descriptive analyses.

\section{Evaluation of Efficacy}

Overall response rate (ORR; complete response (CR) plus partial response $(\mathrm{PR})$ ) was determined in the CNS and non-CNS cases. CNS responses were classified according to modified Response Evaluation Criteria in Solid Tumors (RECIST) [12]. Non-CNS response was also assessed by RECIST. Date of progression was recorded as the first documented progression at any site in either CNS or non-CNS. Patients continued study treatment until they experienced unacceptable toxicity, or until progressive disease (PD) occurred. Progression-free survival (PFS) was the time elapsed from the date of initiation of LC to the date of the first evidence of PD or death in the absence of PD. OS was defined as the period from the first day of treatment until the date of last follow-up or death.

\section{Evaluation of Safety}

Patients were monitored for serious adverse events (SAEs) according to the National Cancer Institute's Common Terminology Criteria for Adverse Events (CTCAE, version 3.0) which grades events as mild (grade 1), moderate (grade 2), severe (grade 3), life-threatening or disabling (grade 4), or fatal (grade 5). Concerning cardiac safety, a cardiac event was defined as a decline in the LVEF that was symptomatic, regardless of the degree of decline or was asymptomatic but with a relative decrease of $20 \%$ or more from baseline to a level below the institution's lower limit of the normal range. Lapatinib was discontinued in patients with symptomatic cardiac events.

\section{Statistical Analysis}

Statistical analysis was carried out using computer software (SPSS version 17.0, SPSS Inc. Chicago, IL, USA). Kaplan-Meier curves were used to estimate DFS and OS, and groups were compared by the log-rank test. All prognostic variables determined to be significant in univariate analysis were included in multivariate analysis using the Cox proportional hazards model. Data were expressed as mean (standard deviation (SD)), minimum-maximum, percent (\%), and 95\% CI where appropriate. A $p$ value of $<0.05$ was considered statistically significant.

\section{Results}

\section{Patients}

Patient demographics and baseline clinical characteristics are summarized in table 1 . The median age was 47 years (range 25-72 years). All patients had multiple BMs. All patients had received prior trastuzumab-based therapies for adjuvant or 
Table 1. Demographic characteristics of patients with brain metastases from HER2+ breast cancer treated with lapatinib and capecitabine

\begin{tabular}{|c|c|}
\hline Age, median (range), years & $47(25-72)$ \\
\hline \multicolumn{2}{|l|}{ ECOG performance status, n (\%) } \\
\hline 0 & $18(21.2)$ \\
\hline 1 & $52(61.2)$ \\
\hline 2 & $14(17.6)$ \\
\hline \multicolumn{2}{|l|}{ Hormone receptor status, n (\%) } \\
\hline ER- and/or PR-positive & $47(55.3)$ \\
\hline ER- and PR-negative & $38(44.7)$ \\
\hline \multicolumn{2}{|l|}{ HER2 positivity, n (\%) } \\
\hline IHC $3+$ & $68(80)$ \\
\hline FISH amplified & $17(20)$ \\
\hline \multicolumn{2}{|l|}{ Extracranial metastases, n (\%) } \\
\hline No & $3(3.5)$ \\
\hline Yes & $82(96.5)$ \\
\hline \multicolumn{2}{|l|}{ Metastatic sites, n (\%) } \\
\hline Liver & $45(52.9)$ \\
\hline Bone & $54(63.5)$ \\
\hline Lung & $35(41.1)$ \\
\hline Other (local, axilla, skin) & $10(1.1)$ \\
\hline \multicolumn{2}{|l|}{ Number of metastatic sites, n (\%) } \\
\hline$<3$ & $38(44.7)$ \\
\hline$\geq 3$ & $47(55.3)$ \\
\hline \multicolumn{2}{|l|}{ Number of prior chemotherapy, $\mathrm{n}(\%)$} \\
\hline (Neo)-adjuvant & $68(80)$ \\
\hline Metastatic 1 & $2(2.4)$ \\
\hline Metastatic 2 & $26(30.6)$ \\
\hline Metastatic 3 & $37(43.5)$ \\
\hline Metastatic $>3$ & $20(23.6)$ \\
\hline \multicolumn{2}{|l|}{ Previous therapy, n (\%) } \\
\hline Anthracyclines & $71(83.5)$ \\
\hline Taxanes & $81(95.2)$ \\
\hline Capecitabine & $13(15.3)$ \\
\hline Vinorelbine & $17(20)$ \\
\hline Gemcitabine & $7(8.2)$ \\
\hline \multicolumn{2}{|l|}{ Trastuzumab-based therapy, n (\%) } \\
\hline Trastuzumab + chemotherapy & $79(93)$ \\
\hline Trastuzumab + endocrine therapy & $6(7)$ \\
\hline Duration of prior trastuzumab, median (range), weeks & $43(7-134)$ \\
\hline \multicolumn{2}{|l|}{ Prior CNS radiation, $\mathrm{n}(\%)$} \\
\hline WBRT only & $85(100)$ \\
\hline SRS only & $0(0)$ \\
\hline
\end{tabular}

$\mathrm{ER}=$ Estrogen receptor; $\mathrm{PR}=$ progesterone receptor; $\mathrm{IHC}=$ immunohistochemistry; FISH = fluorescence in situ hybridization;

$\mathrm{CNS}=$ central nervous system; WBRT $=$ whole brain radiotherapy;

$\mathrm{SRS}=$ stereotactic radiosurgery.

metastatic disease, as well as WBRT. LC was administered as the first-line systemic therapy following WBRT after the development of BMs. Previous treatment with capecitabinebased therapies for metastatic disease was evident in 13 patients. The median duration of previous treatment with trastuzumab was 43 weeks (range 7-134). Of 85 tumors, 47 (55.3\%) were estrogen receptor (ER)- or progesterone receptor (PR)positive, and $38(44.7 \%)$ tumors were negative for both receptors.

\section{Efficacy}

Among all 85 patients, 2 (2.4\%) achieved a CR, 21 (24.7\%) a PR, and 35 (41.2\%) SD; 27 (31.8\%) patients had PD, resulting in an ORR of $27.1 \% .58(68.3 \%)$ patients had clinical benefit $(\mathrm{ORR}+\mathrm{SD})$ (table 2). The described response rates were obtained in the CNS and non-CNS sites. The median
Table 2. Efficacy parameters in patients with brain metastases from HER2+ breast cancer treated with lapatinib and capecitabine $(n=85)$

\begin{tabular}{lc}
\hline End point & \\
\hline Overall survival, median (range), months & $13(9-16.9)$ \\
Progression-free survival median (range), months & $7(5.6-8.3)$ \\
Overall response rate (ORR), n (\%) & $23(27.1)$ \\
Complete response (CR), n (\%) & $2(2.4)$ \\
Partial response (PR), n (\%) & $21(24.7)$ \\
Stable disease (SD), n (\%) & $35(41.2)$ \\
Progressive disease (PD), n (\%) & $27(31.8)$ \\
Clinical benefit rate (ORR + SD), n (\%) & $58(68.3)$ \\
\hline
\end{tabular}

Fig 1. Progressionfree survival. Median PFS was 7 months (95\% Cl 5-9).

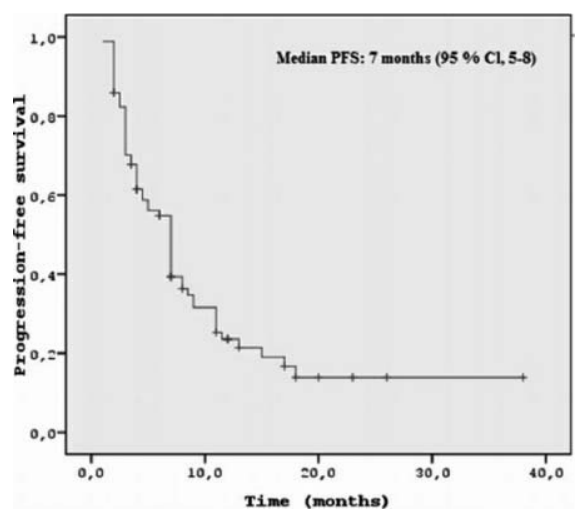

Fig 2. Overall survival. Median OS was 13 months (95\% Cl 9-16).

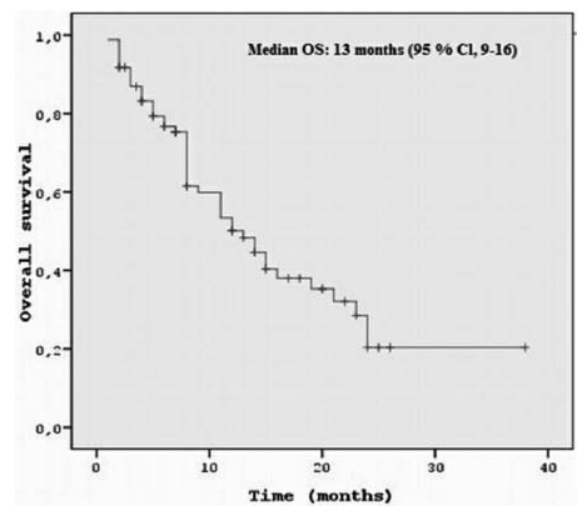

follow-up time from the initiation of LC was 10 months (range 1-38 months). The median duration of treatment with LC was 7 months (range 2-38 months). All 85 patients were included in the analysis of PFS and OS from the start of LC. The median PFS was 7 months (95\% CI 5-10) (fig. 1). At the time of this analysis, 23 of the 85 patients had not yet experienced either intra- or extracranial disease progression and were still receiving LC. 47 patients died, and the median OS from the start of LC was 13 months (95\% CI 9-16) (fig. 2).

\section{Survival Outcomes after the Diagnosis of Brain Metastasis}

All 8 potential predictive covariates with corresponding univariate analyses are presented in table 3. Clinical features that were significantly associated with poor OS included poor performance status, PFS $\leq 6$ months, number of metastatic site $\geq 3$, and failure to respond to treatment according to 
Table 3. Risk factors determining survival after the onset of brain metastasis in HER2-positive metastatic breast cancer

\begin{tabular}{|c|c|c|c|c|c|c|c|}
\hline \multirow[t]{2}{*}{ Parameter } & \multicolumn{2}{|c|}{ Patients, $\mathrm{n}$} & \multirow{2}{*}{$\begin{array}{l}\text { Median OS, } \\
\text { months }\end{array}$} & \multirow{2}{*}{$\begin{array}{l}\text { Log rank } \\
\text { p value }\end{array}$} & \multicolumn{3}{|c|}{ Multivariate analysis } \\
\hline & died & total & & & OR & $95 \% \mathrm{CI}$ & $\mathrm{p}$ value \\
\hline Age & & & & 0.572 & & & \\
\hline$\leq 50$ years & 31 & 54 & 14 & & & & \\
\hline$>50$ years & 16 & 31 & 11 & & & & \\
\hline Number of metastatic site & & & & 0.036 & & & \\
\hline $3<$ & 16 & 38 & 16 & & 1.000 & & \\
\hline $3 \geq$ & 31 & 47 & 12 & & 1.056 & $0.544-2.052$ & 0.872 \\
\hline PFS & & & & 0.0001 & & & \\
\hline$>6$ months & 14 & 39 & 23 & & 1.000 & & \\
\hline$\leq 6$ months & 33 & 46 & 8 & & 4.406 & $2.315-8.387$ & 0.0001 \\
\hline Median duration of prior trastuzumab & & & & 0.627 & & & \\
\hline$>36$ weeks & 26 & 43 & 15 & & & & \\
\hline$\leq 36$ weeks & 21 & 42 & 11 & & & & \\
\hline Therapeutic response & & & & 0.0001 & & & \\
\hline Responders & 22 & 56 & 16 & & 1.000 & & \\
\hline ECOG PS & & & & 0.003 & & & \\
\hline $0-1$ & 34 & 70 & 15 & & 1.000 & & \\
\hline 2 & 13 & 14 & 5 & & 2.212 & $1.156-4.233$ & 0.017 \\
\hline Hormone receptor status & & & & 0.797 & & & \\
\hline ER- and/or PR-positive & 25 & 47 & 14 & & & & \\
\hline ER-and PR-negative & 22 & 38 & 11 & & & & \\
\hline Liver metastases & & & & 0.103 & & & \\
\hline No & 17 & 39 & 19 & & & & \\
\hline Yes & 30 & 46 & 12 & & & & \\
\hline
\end{tabular}

Table 4. Adverse events in patients with brain metastases from HER2+ breast cancer treated with lapatinib and capecitabine

\begin{tabular}{lll}
\hline Adverse event & Any grade, n (\%) & Grade 3-4, n (\%) \\
\hline Hand-foot syndrome & $50(58.8)$ & $8(9.4)$ \\
Diarrhea & $30(35.4)$ & $7(8.3)$ \\
Fatigue & $50(58.9)$ & $5(5.9)$ \\
Nausea & $47(55.3)$ & $6(7.1)$ \\
Rash & $31(36.5)$ & $4(4.7)$ \\
Anorexia & $39(45.9)$ & $3(3.6)$ \\
\hline
\end{tabular}

RECIST criteria. In the resulting Cox proportional hazards model (table 3 ), duration of PFS (> 6months vs. $\leq 6$ months) was determined to be the single adverse prognostic factor that was the independent predictor of short survival $(\mathrm{p}=0.001)$. There was no significant survival advantage after lapatinib treatment in hormone receptor-positive patients compared with hormone receptor-negative patients in terms of PFS (median 7 months in both groups) and OS (median 14 vs. 11 months)

\section{Adverse Events}

All patients were assessable for toxicity. Grade 3 and 4 treatment-related toxicities are listed in table 4 . The most common adverse events were hand-foot syndrome and fatigue which improved with supportive measures and/or dose reductions in most cases. No patient was taken off the treatment because of toxicity. 2 patients experienced grade 4 diarrhea, and 1 patient each experienced grade 4 anorexia, stomatitis, rash, and fatigue. Concerning cardiac surveillance and cardiotoxic- ity, none of the patients developed symptomatic congestive heart failure or an asymptomatic decline in LVEF to less than $50 \%$.

\section{Discussion}

The CNS is an important sanctuary site for metastatic dissemination causing substantial morbidity and mortality in patients with HER2+ MBC. Our retrospective evaluation of safety and efficacy of LC in this population with BMs showed a $27.1 \%$ ORR similar to previous experience in the literature [12-17]. Moreover, survival outcomes including PFS of 7 months and OS of 13 months were similar to the literature confirming the efficacy of LC in BMs of HER2+ MBC patients.

BMs are common in HER2+ MBC. However, it remains unanswered whether the high frequency of BMs is merely related to the aggressiveness of HER2+ disease. Nevertheless, the observation is very relevant, and novel agents more efficient at penetrating the CNS to prevent or treat CNS metastases are urgently needed. It has been suggested that lapatinib may decrease the risk of developing CNS metastases. In a preclinical study by Palmieri et al. [18], lapatinib was reported to inhibit the formation of metastases in HER2+ human breast carcinoma cells. In accordance with this observation, several studies have reported efficacy of LC combination treatment in this patient population [13-17]. 
Table 5. Literature review of lapatinib use in patients with brain metastases from breast cancer

\begin{tabular}{llrcc}
\hline Study [ref.] & Regimen & $\mathrm{n}$ & ORR, \% & PFS, months \\
\hline Lin et al. 2008 [12] & lapatinib & 39 & 2.6 & 3.0 (TTP) \\
Boccardo et al. 2008 [13] & lapatinib + capecitabine & 138 & 18.0 & NR \\
Lin et al. 2009 [14] & lapatinib & 237 & 6.0 & 2.4 \\
Lin et al. 2009 [14] & lapatinib + capecitabine & 50 & 20.0 & 3.65 \\
Sutherland et al. 2010 [15] & lapatinib + capecitabine & 34 & 21.0 & 5.3 \\
Metro et al. 2011 [16] & lapatinib + capecitabine & 30 & 31.8 & NR \\
Bachelot et al. 2011 [17] & lapatinib + capecitabine & 45 & 67.0 & 5.6 \\
Our study & lapatinib + capecitabine & 85 & 27.1 & NR \\
\hline
\end{tabular}

ORR = Overall response rate; PFS = progression-free survival; OS = overall survival; TTP = time to progression; $\mathrm{NR}=$ not reported .

In a phase III study evaluating capecitabine versus LC therapy in MBC patients, the addition of lapatinib was shown to be associated with a reduced incidence of BMs as the first site of relapse, which has been considered as a preventive effect $[9,11]$. Lapatinib has also been suggested to be administered concurrently with cranial radiotherapy, due to the preclinical data indicating that lapatinib may act as a radiosensitizer [19].

Selected studies of systemic therapy with lapatinib for BMs from HER2+ MBC are summarized in table 5 [12-17]. A total of 6 studies were reviewed. All but 1 study used capecitabine in addition to single-agent lapatinib. 2 studies were retrospective subgroup evaluations of the Lapatinib Expanded Access Program [13, 15], and 1 study was a retrospective analysis from Italy [16]. The remaining 2 reports were prospective phase II trials $[14,17]$. Notably, the Landscape trial including 45 patients with BMs from HER2+ MBC involved the use of LC in the first-line treatment before WBRT [17]. The authors reported a stunning $67 \%$ ORR with a time to progression (TTP) of 5.5 months. The only phase II study using LC after WBRT reported a $20 \%$ ORR with a PFS of 3.65 months [14]. OS duration is generally lacking in all these studies except for the retrospective Italian study [16] which reported 11 months of OS, very similar to our finding. Overall, these studies reported ORRs in the range of $18-67 \%$, and DFS or TTP of
3.65-5.6 months. Our results including a 27.1\% ORR, 7-month PFS, and 13-month OS are in accordance with these reports indicating efficacy of LC in these patients. The most frequent adverse events were hand-foot syndrome, nausea, and fatigue. Most events were mild and resolved without the need for dose modification. Notably, cardiac side effects were absent. The LC combination was well-tolerated with an acceptable side effect profile.

In conclusion, modern therapies with better efficacy have led to a change in the prevalence and clinical significance of BMs from HER2+ MBC. The current standard of care in these patients still comprises WBRT and other local modalities such as stereotactic radiosurgery or conventional neurosurgery for oligometastases. Because trastuzumab is relatively ineffective in $\mathrm{BMs}$, the most promising systemic treatment after WBRT appears to be LC combination therapy after progression on trastuzumab. However, clinical experience with lapatinib in this setting is limited, and more effective novel modalities are urgently required for BMs from HER2+ MBC.

\section{Disclosure Statement}

There is no conflict of interest.

\section{References}

1 Slamon DJ, Clark GM, Wong SG, Levin WJ, Ullrich A, McGuire WL: Human breast cancer: correlation of relapse and survival with amplification of the HER-2/neu oncogene. Science 1987; 235:177-82.

2 Bendell JC, Domchek SM, Burstein HJ, Harris L, Younger J, Kuter I, Bunnell C, Rue M, Gelman R, Winer E: Central nervous system metastases in women who receive trastuzumab-based therapy for metastatic breast carcinoma. Cancer 2003;97:29727.

3 Clayton AJ, Danson S, Jolly S, Ryder WD, Burt PA, Stewart AL, Wilkinson PM, Welch RS, Magee B, Wilson G, Howell A, Wardley AM: Incidence of cerebral metastases in patients treated with trastuzumab for metastatic breast cancer. $\mathrm{Br} \mathrm{J}$ Cancer 2004;91:639-43.

4 Pestalozzi BC, Brignoli S: Trastuzumab in CSF J Clin Oncol 2000;18:2349-51.
5 Stemmler HJ, Schmitt M, Willems A, Bernhard H, Harbeck N, Heinemann V: Ratio of trastuzumab levels in serum and cerebrospinal fluid is altered in HER2-positive breast cancer patients with brain metastases and impairment of blood-brain barrier. Anticancer Drugs 2007;18:23-8.

6 Bria E, Cuppone F, Fornier M, Nisticò C, Carlini P, Milella M, Sperduti I, Terzoli E, Cognetti F, Giannarelli D: Cardiotoxicity and incidence of brain metastases after adjuvant trastuzumab for early breast cancer: the dark side of the moon? A metaanalysis of the randomized trials. Breast Cancer Res Treat 2008;109:231-9.

7 Trudeau ME, Crump M, Charpentier D, Yelle L, Bordeleau L, Matthews S, Eisenhauer E: Temozolomide in metastatic breast cancer (MBC): a phase II trial of the National Cancer Institute of Canada-Clinical Trials Group (NCIC-CTG). Ann Oncol 2006;17:952-6.
8 Rivera E, Meyers C, Groves M, Valero V, Francis D, Arun B, Broglio K, Yin G, Hortobagyi GN, Buchholz T: Phase I study of capecitabine in combination with temozolomide in the treatment of patients with brain metastases from breast carcinoma. Cancer 2006;107:1348-54.

$\checkmark$ Geyer CE, Forster J, Lindquist D, Chan S, Romieu CG, Pienkowski T, Jagiello-Gruszfeld A, Crown J, Chan A, Kaufman B, Skarlos D, Campone M, Davidson N, Berger M, Oliva C, Rubin SD, Stein S, Cameron D: Lapatinib plus capecitabine for HER2-positive advanced breast cancer. N Engl J Med 2006;355:2733-43.

10 Polli J, Humphreys JE, Harmon KA, Castellino S, O'Mara MJ, Olson KL, John-Williams LS, Koch KM, Serabjit-Singh CJ: The role of efflux and uptake transporters in [N-\{3-chloro-4-[(3-fluorobenzyl)oxy]phenyl\}-6-[5-(\{[2-(methylsulfonyl) ethyl]amino\} methyl)-2-furyl]-4-quinazolinamine (GW572016, lapatinib) disposition and drug interactions. Drug Metable Dispos 2008;36:695-701. 
11 Cameron D, Casey M, Press M, Lindquist D, Pienkowski T, Romieu CG, Chan S, JagielloGruszfeld A, Kaufman B, Crown J, Chan A, Campone M, Viens P, Davidson N, Gorbounova V, Raats JI, Skarlos D, Newstat B, Roychowdhury D, Paoletti P, Oliva C, Rubin S, Stein S, Geyer CE: A phase III randomized comparison of lapatinib plus capecitabine versus capecitabine alone in women with advanced breast cancer that has progressed on trastuzumab: updated efficacy and biomarker analyses. Breast Cancer Res Treat 2008; 112:533-43.

$\checkmark 12$ Lin NU, Carey LA, Liu MC, Younger J, Come SE, Ewend M, Harris GJ, Bullitt E, Van den Abbeele AD, Henson JW, Li X, Gelman R, Burstein HJ, Kasparian E, Kirsch DG, Crawford A, Hochberg F, Winer EP: Phase II trial of lapatinib for brain metastases in patients with human epiderma growth factor receptor 2-positive breast cancer. J Clin Oncol 2008; 26:1993-9.

13 Boccardo F, Kaufman B, Baselga J, Dieras J, Link J, Casey MA, Fittipaldo A, Oliva C, Zembryki D, Rubin SD: Evaluation of lapatinib plus capecitabine in patients with brain metastases from HER2+ breast cancer enrolled in the Lapatinib Expanded Access Program (LEAP) and French Authorisation Temporaire d'Utilization (ATU). J Clin Oncol 2008;26(suppl):abstr 1094

14 Lin NU, Dieras V, Paul D, Lossignol D, Christodoulou C, Stemmler HJ, Roché H, Liu MC, Greil R, Ciruelos E, Loibl S, Gori S, Wardley A, Yardley D, Brufsky A, Blum JL, Rubin SD, Dharan B, Steplewski K, Zembryki D, Oliva C, Roychowdhury D, Paoletti P, Winer EP: Multicenter phase II study of lapatinib in patients with brain metastases from HER2-positive breast cancer. Clin Cancer Res 2009;15:1452-9.

15 Sutherland S, Ashley S, Miles D, Chan S, Wardley A, Davidson N, Bhatti R, Shehata M, Nouras H, Camburn T, Johnston SRD: Treatment of HER2-positive metastatic breast cancer with lapatinib and capecitabine in the lapatinib expanded access programme, including efficacy in brain metastases - the UK experience. Br J Cancer 2010;102:995-1002.

16 Metro G, Foglietta J, Russillo M, Stocchi L, Vidiri A, Giannarelli D, Crino L, Papoldo P, Mottolese M, Cognetti F, Fabi A, Gori S: Clinical outcome of patients with brain metastases from HER2-positive breast cancer treated with lapatinib and capecitabine. Ann Oncol 2011;22:625-30.

17 Bachelot TD, Romieu, G, Campone, M, Dieras V, Cropet C, Roche HH, Jimenez M, Le Rhun E, Pierga J, Gonçalves A, Leheurteur M, Domont J, Gutierrez M,Cure H,Ferrero C, Labbe C: LANDSCAPE: an FNCLCC phase II study with lapatinib and capecitabine in patients with brain metastases from HER2-positive metastatic breast cancer before whole brain radiotherapy. J Clin Oncol 2011; 29:47s(abstr 509).

18 Palmieri D, Gril BM, Herring J, et al.: Lapatinib prevents the metastatic colonization of EGFR+ and Her-2+ breast cancer cells in the brain. Breast Cancer Res Treat 2007;106(suppl 1):S30(abstr 210).

19 Zhou H, Kim YS, Peletier A, McCall W, Earp HS, Sartor CI: Effects of the EGFR/HER2 kinase inhibitor GW572016 on EGFR- and HER2-overexpressing breast cancer cell line proliferation, radiosensitization, and resistance. Int $\mathrm{J}$ Radiat Oncol Biol Phys 2004;58:344-52. 